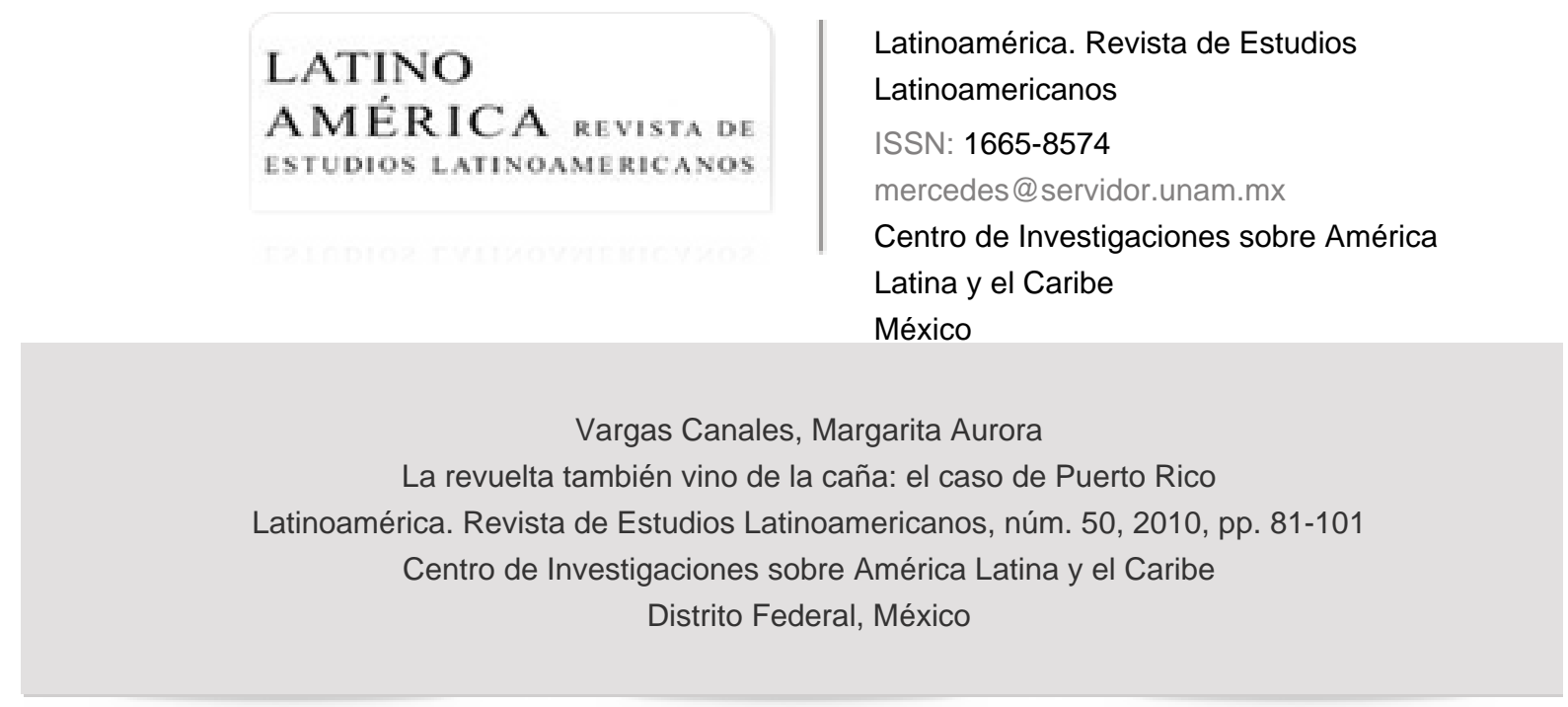

Disponible en: http://www.redalyc.org/articulo.oa?id=64014997006

- Cómo citar el artículo

- Número completo

- Más información del artículo

- Página de la revista en redalyc.org

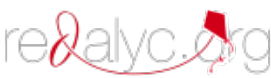

Sistema de Información Científica

Red de Revistas Científicas de América Latina, el Caribe, España y Portugal Proyecto académico sin fines de lucro, desarrollado bajo la iniciativa de acceso abierto 


\title{
La revuelta también vino de la caña: el caso de Puerto Rico
}

\author{
Margarita Aurora Vargas Canales*
}

Resumen: El texto se centra en explicar las vinculaciones políticas de los campesinos cañeros con el nacionalismo, en el marco de las huelgas cañeras de 1934. El artículo presenta un panorama histórico de la década de 1930 en el Caribe insular para introducir la situación de Puerto Rico en esos años. Las huelgas cañeras de 1934 fueron la única oportunidad histórica de la clase obrero-campesina puertorriqueña de unirse al nacionalismo de Pedro Albizu Campos. Los movimientos del 34 fueron un factor importante que abrió la perspectiva de los trabajadores cañeros hacia otras opciones políiticas, como el comunismo y el nacionalismo.

Palabras clave: Caña de azúcar, Nacionalismo, Huelgas de campesinos cañeros, Historia social, Movimientos sociales.

ABSTRAC: This text focuses on the links between the nationalism and the sugar cane workers during the strikes of 1934. It presents a historical panorama of the 1930 decade in the Caribbean Islands. The sugar strikes of 1934 were the only historical sugar cane worker's chance to join Pedro Albizu's nationalistic ideas. The 1934's movements were an important element to open political options (communism, nationalism) for the sugar workers.

Key worDs: Sugar cane, Nationalism, Sugar workers strikes, Social history, Social movements.

* Centro de Investigaciones sobre América Latina y el Caribe, unam (maryagua02@yahoo.com.mx). 
Nuestra existencia no se debe al producto de una loca aventura, sino a tono con la necesidad de estos tiempos en marcha hacia una sociedad nueva, cuyo pronto advenimiento quiérese retardar a favor de un limitado grupo de privilegiados, en detrimento de una mayoría que es imposible ignorar.

"Manifiesto pro-Afirmación Socialista", en Unión Obrera, 30 de enero de 1934.

\section{INTRODUCCIÓN}

a década de 1930 en el Caribe insular representa un complicado juego de luchas, intereses y disputas por el poder, tanto al interior de cada una de las islas como en relación con los aún centros metropolitanos. Las tensiones entre los distintos actores políticos, las estrategias diseñadas en el exterior y las poblaciones a las que éstas se aplicaron generaron dinámicas de lucha y resistencia para algunos sectores como los campesinos de la caña y los trabajadores de los muelles.

El descontento se manifestó en cada isla de manera particular, y no en todos los movimientos el sector obrero o campesino tuvo un papel protagónico. Cuba vivió un proceso donde se conjugaron el repudio al régimen de Gerardo Machado, los efectos de la crisis económica de 1929 y la organización de estudiantes y clases medias, que terminaron con la caída del dictador. República Dominicana entró a un periodo de terror y privilegios para otros durante la larga dictadura de Rafael Leónidas Trujillo (iniciada en 1930). El Caribe anglófono enfrentó la crisis a través de huelgas contra el desempleo y el hambre y, en algunos casos, con un movimiento organizado particularmente entre los trabajadores bananeros en Jamaica y los petroleros en Trinidad. ${ }^{1}$ El Caribe francófono al igual que el

1 Véase Nigel Bolland, On the march. Labour rebellions in the British Caribbean 1934-1939, Londres, James Currey Publishers, 1995. 
anglófono, todavía dependientes de sus metrópolis, vivieron la creación de las primeras organizaciones y posteriormente partidos comunistas, ${ }^{2}$ aunado a la realización de huelgas en la industria del azúcar.

El presente artículo tiene como propósito analizar una serie de huelgas de los trabajadores cañeros puertorriqueños en 1934, para encontrar las posibles aristas y nexos de estos movimientos con el discurso nacionalista y el comunismo. Las huelgas del "34" ofrecen la posibilidad de encontrar estas conexiones o desencuentros porque es la única vez en la historia contemporánea de Puerto Rico en la que un movimiento "obrero-campesino" acudió a un líder nacionalista para dirigir sus luchas.

Las huelgas de 1934 se inscribieron en un proceso histórico de transición para Puerto Rico. La modernización económica y política de esta isla comenzaba a ser un proyecto para el gobierno de Estados Unidos. La idea de modernización fue compartida por algunos sectores de las clases económicamente dirigentes y profesionales puertorriqueñas. Los campesinos cañeros vivieron este proceso de una manera distinta, aunque sostengo la hipótesis que ellos, a su manera, también compartieron una aspiración de modernización.

\section{LA DÉCADA DEL TREINTA, LA DÉCADA ROJA}

En enero de 1934, miles de trabajadores de la caña en Puerto Rico se fueron a huelga. El motivo principal era exigir mejores condiciones laborales y desconocer un acuerdo que habían negociado sus líderes pertenecientes a la Federación Libre de los Trabajadores (FLT) con la parte patronal: los representantes de las colonias y centrales azucareras.

Los trabajadores en huelga rechazaron las negociaciones que, en su nombre, había hecho Rafael Alonso Torres, dirigente de la flT, y se acercaron al líder nacionalista Pedro Albizu Campos ${ }^{3}$ para proponerle que abanderara su movimiento. El presidente del Partido Nacionalista aceptó la propuesta.

2 Véase Paul Butel, Histoire des Antilles Françaises XVIIe -XX e siècle, París, Editions Perrin, 2002.

3 Pedro Albizu Campos nació en Ponce a finales del siglo xIX, estudió leyes en Estados Unidos, ingresó al Partido Nacionalista del que se convirtió en presidente en 1930. Antes de este cargo 
Por primera vez en la historia contemporánea de esta isla caribeña, la opción política más radical - en cuanto a su crítica al colonialismo de Estados Unidos y a la defensa de la independencia- el nacionalismo, se unía a las luchas de los campesinos y obreros que laboraban en la industria del azúcar.

Durante esta década, otros trabajadores puertorriqueños iniciaron una ola de huelgas: las trabajadoras de la industria de la aguja, los estibadores de los muelles, los panaderos, los conductores de taxis y camionetas o trucks de pasajeros, además de los estudiantes universitarios. En 1934, la amenaza de una gran huelga general era motivo de preocupación para el gobierno estadounidense y el sector patronal, conformado también por industriales, comerciantes y dueños de colonias puertorriqueños.

El gran cuestionamiento de estos sectores era la carestía de la vida en relación con los bajos salarios. Esta población en el fondo, desde su experiencia cotidiana, reclamaba un trato más justo y mejores condiciones de vida. Las peticiones eran una clara evidencia de su inconformidad respecto de la política colonial impuesta a las clases trabajadoras, por el gobierno de Estados Unidos.

La dinámica económica se generó, por una parte, debido a las leyes y medidas adoptadas por la administración estadounidense, ${ }^{4}$ y por otra, por las

viajó por los países latinoamericanos pidiendo ayuda para lograr la independencia de Puerto Rico. En 1936 es arrestado y enviado a prisión a Atlanta, en 1947 regresa a Puerto Rico. En 1950 el presidente Harry Truman sufre un atentado y se responsabiliza a los nacionalistas. Pedro Albizu vuelve a ser arrestado esta vez en Puerto Rico. Luis Muñoz Marín, como gobernador, lo indulta en 1953, nuevos atentados hacen que Muñoz Marín revoque el indulto en 1954. Finalmente, muere en 1965, después de varios años en prisión y de haber sufrido tortura por sus convicciones políticas.

4 Desde que el gobierno estadounidense tomó posesión de la isla (1898), se instrumentaron acuerdos para regular el comercio entre Puerto Rico y Estados Unidos. Puerto Rico, que atravesaba por una mala situación agrícola ya que justo acababa de pasar el Huracán San Ciprián y se habían perdido las cosechas de tabaco, fue sometido a un sistema de comercio desigual, donde los productos puertorriqueños eran gravados con impuestos por parte de Estados Unidos. Puerto Rico perdió sus principales clientes que eran España y Europa, compradores de café. Estas leyes están contenidas en la Ley Foraker de 1905, en el libro de Comercio. Véase J. Gould Lyman, La Ley Foraker: raíces de la política colonial, traducido del inglés por Jorge Luis Morales, Río Piedras, Editorial Universitaria, 1975 (Col. upRET, Serie de Estudios Sociales), 284 
circunstancias fortuitas como el huracán San Felipe que tuvo lugar en 1928, estos factores provocaron la destrucción de fincas cafetaleras y de tabaco, los otros dos grandes cultivos de exportación en Puerto Rico. El cultivo de caña de azúcar, poco a poco, fue sustituyendo a los otros dos. ${ }^{5}$ La abundante mano de obra en este renglón hacía que el trabajo fuera menos cotizado y los trabajadores eran fácilmente reemplazados, se tenía la sensación de que la caña abarcaba todo, devoraba la tierra y los brazos de quienes la sembraban.

Los éxodos de campesinos de la altura o la montaña a la bajura o costa se hicieron más frecuentes. La migración de trabajadores de las ciudades o pueblos a las centrales y colonias también tuvo lugar, transformando a obreros desempleados en cortadores, sembradores, regadores y cargadores de caña. La mano de obra disponible en los lugares de siembra y cultivo era abundante, lo que contribuía a abaratarla aún más.

Las huelgas cañeras de 1934 se inscriben en un proceso de conversión de Puerto Rico de una agricultura diversificada (tabaco, café, caña, cocos, hortalizas y frutos menores), con unidades productivas de pequeña a mediana extensión, ${ }^{6}$ al monocultivo de la caña de azúcar, en colonias subsidiarias de las centrales y en fincas o extensiones cultivables pertenecientes a las mismas corporaciones.

pp., y Carmen Raffucci de García, El gobierno civil y la Ley Foraker: antecedentes históricos, Río Piedras, Puerto Rico, Editorial Universitaria, 1981, 145 pp.

5 En el Censo de Puerto Rico, 1935: población, ed. bilingüe inglés/español, San Juan, Reconstruction Admnistration Oficina del Censo, 1936, 10 apartados de 15 a 20 páginas cada uno, con mapa de Puerto Rico y sus municipios, se contabilizaron 7089 fincas de caña con 245154 cuerdas cultivadas, frente a 21125 fincas de café con 182316 cuerdas cultivadas y 17086 fincas de tabaco con 45729 cuerdas cultivadas, p. 15. Según este conteo había más fincas de café y tabaco que de caña, pero más cuerdas cultivadas de caña. El problema radica en que una finca, según el censo, era una extensión de tierra cultivable mayor de 3 cuerdas, el café y el tabaco se elaboraban en fincas de pequeña a mediana extensión, la caña se producía a gran escala en fincas de más de 500 acres, o sea los terrenos de las corporaciones. Los encuestadores del censo no tuvieron acceso a las propiedades de las centrales.

6 En el Censo de Población..., p. 2, se define una finca como: "la compone toda la tierra explotada directamente por una persona, ya sea trabajando sola o con la ayuda de su familia o empleados a sueldo. La tierra explotada por una sociedad mercantil o una corporación se considera también una finca, ésta será mayor de tres cuerdas". 
El cambio de modelo económico respondió, también, a las necesidades y prioridades del sistema colonial, donde las élites del gobierno estadounidense propusieron, analizaron y debatieron diferentes alternativas para Puerto Rico, ${ }^{7}$ conjuntamente con algunos especialistas puertorriqueños. La forma en que dichas propuestas fueron puestas en vigor dañó de diferentes maneras a la población puertorriqueña. Los campesinos, en general, y no sólo quienes se dedicaban al cultivo de la caña fueron, probablemente, la clase social que resultó más afectada.

\section{LOS MOVIMIENTOS CAÑEROS Y IA COMUNIDAD PUERTORRIQUEÑA EN NUEVA YORK}

Las diversas huelgas cañeras en Puerto Rico, que se llevaron a cabo desde principios del siglo xx, fueron apoyadas económica y emocionalmente por miembros de la comunidad puertorriqueña en Nueva York. Estas organizaciones, que formaron los distintos núcleos de residentes en la urbe de hierro, eran un conglomerado heterogéneo. La gama era amplia: desde los círculos anarquistas, los comités de adhesión a los partidos Republicano, Demócrata o Socialista estadounidenses, la Asociación Nacionalista, vinculada al Partido Nacionalista Puertorriqueño, hasta las asociaciones de profesionales con fines artísticos y culturales.

Los periódicos, que se publicaban en español ${ }^{8}$ en esa ciudad, circulaban entre las comunidades de torcedores de tabaco hispanohablantes: puertorri-

7 En el marco del Nuevo Trato para la industria del azúcar se propuso el Plan Chardón con la idea de formar empresas gubernamentales o centrales del gobierno. Hubo otra propuesta para utilizar todos los componentes de la caña de azúcar, incluido el bagazo, y establecer industrias al respecto. Véase Thomas Mathews, La politica puertorriqueña y el Nuevo Trato, trad. del inglés por Antonio J. Colorado, San Juan, Departamento de Instrucción Pública, 1967, 237 pp. y Documento Chart: "Possibilities that exist for additional agriculture industrial enterprises in Porto Rico", Puerto Rico Reconstruction Administration (PRRA), destinatario: Gobierno de Puerto Rico, 1937 (Col. Puertorriqueña de la Universidad de Puerto Rico, recinto Río Piedras), ms. núm. 246.

8 De acuerdo con la información recabada por Bernardo Vega en Memorias de Bernardo Vega: contribución a la bistoria de la comunidad puertorriqueña en Nueva York, editadas por César Andreu Iglesias, $4^{a}$ ed., Río Piedras, Puerto Rico, Ediciones Huracán, 2002, 278 pp., mediante entrevista a Pedro Juan Bonit, tabaquero puertorriqueño residente en Nueva York desde 1913, los periódicos que se publicaban en español eran: Las Novedades, "publicación española cuyo director era un tal García, el semanario anarquista Cultura Proletaria y La Prensa, entonces semanario", p. 133. 
queños, cubanos y españoles, principalmente. La función más importante de este medio de comunicación era dar cohesión a las campañas o colectas organizadas por algunas asociaciones, para ayudar a sostener las huelgas de trabajadores de la caña en Puerto Rico.

Una tendencia entre los dirigentes obreros y, sobre todo, entre los tabaqueros socialistas era el internacionalismo, es decir, considerar que las causas de los trabajadores constituían un movimiento que hermanaría a todos los trabajadores del mundo. De acuerdo con esta concepción, la lucha trascendía las fronteras nacionales, por tal motivo, la solidaridad al apoyar las huelgas o movimientos de protesta en otras partes del mundo era fundamental, incluso, las luchas contra los regímenes autoritarios o dictatoriales. Un socialista se consideraba, en cierto sentido, ciudadano del mundo, como dijera Bernardo Vega: "su trinchera estaba en cualquier lugar del mundo".

Tanto en Nueva York como en Puerto Rico, hacia 1932, había un debate intenso en torno a la validez del socialismo puertorriqueño como alternativa a las causas de los trabajadores. En Puerto Rico, la alianza pactada por el Partido Socialista con el Partido Republicano para las elecciones de 1932, fue un hecho que cuestionó profundamente, tanto a los dirigentes de uniones agrícolas como a trabajadores de la caña, sobre el compromiso del socialismo boricua para con los trabajadores.

Otras opciones políticas comenzaron a tomar mayor fuerza entre la clase trabajadora puertorriqueña. Por un lado, el comunismo adquirió más presencia en este sector radicado en Nueva York ${ }^{9}$ y entre algunos periodistas e intelectuales

9 Recuérdese que el Partido Comunista estadounidense se había formado desde 1917, propiciado por el éxito de la Revolución rusa. El Partido Comunista de Estados Unidos tuvo una actividad política más intensa durante la "década roja", la de 1930, debido a la represión de que fueron objeto los trabajadores en huelga: los mineros, de la industria textil, los cargadores de los muelles de la Costa Oeste, quienes, brutalmente perseguidos y castigados, radicalizaron sus ideas transitando del socialismo al comunismo. Un ejemplo conocido es el grupo de mineros irlandeses conocidos como los "Molly Maguires", véase Andrés Linares, Historia de los grupos de izquierda en los Estados Unidos, Madrid, Castellote Editor, 1976, 200 pp. Por otro lado, después de la disidencia entre el Partido Socialista Puertorriqueño, propiciada fundamentalmente por la huelga de 1934 y Afirmación Socialista, se creó en 1935 el Partido Comunista Puertorriqueño. 
puertorriqueños,$^{10}$ conjuntamente con algunas uniones de trabajadores como las de estibadores de los muelles. Asimismo, el Partido Nacionalista, con su líder Lic. Pedro Albizu Campos, empezó a establecer conexiones en Nueva York, donde se formó la Asociación Nacionalista. En Puerto Rico da inicio la aparición de artículos periodísticos decididamente nacionalistas, ${ }^{11}$ aunque, en realidad para los campesinos cañeros la figura del orador más convincente de Ponce, adquirió una dimensión relevante, hasta que le fue propuesto el liderato de la huelga cañera de 1934.

Había diferencias sustanciales entre los militantes puertorriqueños del nacionalismo y del comunismo. Mientras que para los nacionalistas el supremo ideal era la independencia, por encima de la emancipación económica y cultural de los trabajadores como clase social, para los comunistas la razón de ser de su ideología era, primero que nada, la cohesión de la clase trabajadora para que pudiera tomar el poder, antes que cualquier causa nacional.

Los campesinos cañeros de las huelgas del 34, habían sido simpatizantes, algunos militantes del Partido Socialista Puertorriqueño (PS) ${ }^{12}$ algunos de ellos fueron militantes, otros no estaban afiliados a ningún partido político pero sí pertenecían a uniones agrícolas, algunas federadas, es decir, afiliadas a la FLT, otras

${ }^{10}$ Entre ellos se encontraban Luis Vergne Ortiz y Eugenio Font Suárez, quienes contrarrestaban los ataques que hacía C. Martínez Acosta en detrimento del comunismo. Véanse los artículos del periódico El Mundo que documentan este debate: C. Martínez Acosta, "Combatiendo el comunismo", 22 de septiembre de 1933; Eugenio Font Suárez, "Defensa Comunista", 21 de septiembre, 1933, p. 2 y el artículo del mismo nombre con fecha 25 de septiembre de 1933, p. 2.

${ }^{11}$ Martín Avilés Bracero publicó “Socialismo y Nacionalismo", en El Mundo, 28 de enero de 1934, p. 4, en éste critica abiertamente el socialismo que existía en Puerto Rico: "Vemos por estas líneas transcritas que el socialismo boricua es un sostenedor del imperialismo norteamericano en Puerto Rico. Ha sido éste el más dócil instrumento del que se ha valido el Gobierno yanqui para desorientar a las huestes obreras, con la prédica de un norteamericanismo suicida: el socialismo en las colonias ha sido siempre una organización antiimperialista. En nuestro país es todo lo contrario $[\ldots] "$.

${ }^{12}$ El Partido Socialista Puertorriqueño (PS) fue creado en 1915 con el propósito de funcionar como el brazo político de la fLT. Los otros partidos políticos eran el Partido Republicano, tradicionalmente el partido de los hacendados más conservadores, fundado por el intelectual de origen africano Celso Barbosa. El Partido Unión era el partido también de los ex hacendados pero más liberales, este partido en su ala más radical contaba con los independentistas, uno de sus principales líderes fue Luis Muñoz Rivera. 
independientes. Sin embargo, tradicionalmente, antes de 1934, el nacionalismo y las ideas comunistas tenían pocos simpatizantes entre quienes cultivaban caña.

Los movimientos que tuvieron lugar durante este año tuvieron resonancias e intercambios con la comunidad trabajadora de Nueva York. En Puerto Rico, las huelgas del 34 pusieron en evidencia el interés de la dirigencia de la flt por firmar un acuerdo, con la parte patronal, que aseguraba la "paz industrial", objetivo primordial del gobierno estadounidense y de los dueños de centrales y colonias, pero que dejaba las demandas de los trabajadores sin una respuesta positiva.

La lucha de los trabajadores en contra del Acuerdo Azucarero de sus propios dirigentes y compañeros que estaban a favor del citado documento fue una lucha sin cuartel. Todos los recursos humanos, organizativos y logísticos de la fLT fueron utilizados en una campaña de difusión, cuyo objetivo era convencer a los campesinos y obreros de la caña de las "bondades" del Acuerdo.

Los mítines o encuentros en las plazas públicas, en las casas de las uniones agrícolas, e incluso en las calles fueron los lugares de enfrentamiento entre los enviados de la fLT y aquellos que denunciaban los inconvenientes de aceptar el Acuerdo, firmado por los líderes de esta organización. Una lucha verbal, que dejó algunos heridos y otros tantos muertos, se desató entre estas dos fracciones. La gran mayoría de los campesinos y obreros de la industria del azúcar experimentaron una gran confusión e incertidumbre.

La disidencia se hizo pública y oficial con la formación de un grupo de trabajadores cañeros que se llamó Afirmación Socialista, ${ }^{13}$ sus miembros fueron expulsados tanto de la fLT como del ps. Ellos proponían la renovación moral de la dirigencia de esta organización, y el regreso a los verdaderos orígenes del socialismo puertorriqueño.

Las ideas expresadas por los miembros de Afirmación Socialista no encontraron eco al interior de la FLT, ni mucho menos dentro del Ps. La represión gubernamental contra los movimientos laborales cañeros y la campaña a favor

${ }^{13}$ Entre ellos se encontraban Tadeo Rodríguez, Luis V. Pino, Lic. José Soto Rivera, Miguel Bernard Silva, Florencio Cabello, Julio Enrique Pantoja y A. Dupont de Jesús, quienes firmaron la invitación al mitin socialista de la Plaza Baldorioty, "Mitin socialista en la Plaza Baldorioty", en Unión Obrera, 16 de enero, 1934. 
del Acuerdo Azucarero produjeron confusión entre los trabajadores. Una considerable fracción de estos cañeros disidentes radicalizó sus posturas políticas y se unió al nacionalista Pedro Albizu Campos, otros ayudaron a fundar el Partido Comunista Puertorriqueño. La inmensa mayoría de los campesinos que cultivaban caña permaneció al margen de la militancia en los partidos políticos.

En Nueva York, la comunidad puertorriqueña, a través de sus organizaciones, continuó manteniendo comunicación con los trabajadores puertorriqueños en huelga, fueran cañeros, estibadores o trabajadoras de la aguja. La organización de campañas y colectas a favor de estos movimientos ${ }^{14}$ prosiguió durante varios años más, a pesar de los problemas que enfrentaban los miembros de esta comunidad en la gran urbe de hierro: alza en el alquiler de viviendas, discriminación racial, pobreza, falta de ayuda (reliefs), por parte del gobierno, a través de los programas del Nuevo Trato, etcétera.

\section{LAS HUELGAS CAÑERAS PUERTORRIQUEÑAS DENTRO DEL CONTEXTO MUNDIAL}

La década de 1930 en Puerto Rico no solamente fue la década roja en el sentido de la proliferación de movimientos de protesta: huelgas, manifestaciones públicas, intentos de asesinato al gobernador estadounidense, creación de partidos políticos cuyo discurso y propuestas señalaban una crítica al colonialismo y proclamaban como alternativa una opción más radical: la independencia o el comunismo, también fue una década de cambios en la óptica del gobierno estadounidense respecto de su colonia hispánica en el mar Caribe.

${ }^{14}$ Bernardo Vega, en sus Memorias..., describe la reacción de la comunidad puertorriqueña en Nueva York cuando fueron procesados, en 1936, Pedro Albizu Campos, Juan Antonio Correjter, Erasmo Velázquez, Clemente Soto Vélez, Juan Gallardo Santiago, Julio H. Velázquez y Luis F. Velázquez, nacionalistas todos y condenados a prisión por el gobierno estadounidense por el delito de motín y traición a la patria: "La comunidad puertorriqueña de Nueva York se llenó de ira al conocer la noticia de la condena. En todas las barricadas surgieron, casi espontáneamente, actos de protesta. Prácticamente todas las agrupaciones existentes, en esa época, se sumaron en la lucha a favor de los presos políticos. Vale apuntar, entre otras, la Mutualista Obrera Puertorriqueña, las Secciones de Harlem del Partido Comunista, el Centro Obrero Español, la Unión Industrial de Tabaqueros y el Comité contra el Fascismo y la Guerra. La Junta Nacionalista en Nueva York recibió innumerables testimonios de adhesión", p. 222. 
La crisis económica de 1929, conocida como la Gran Depresión en Estados Unidos, provocó un clima de desesperación e incertidumbre en la mayoría de la población, por primera vez en la historia de la ya primera potencia mundial, los ciudadanos no podían confiar ni en sus instituciones, ni en sus gobernantes. El cisma financiero, el desempleo y la ruina económica de miles de personas era la única realidad visible.

En Estados Unidos la campaña electoral del candidato por el Partido Demócrata, Franklin Delano Roosevelt, destacaba la esperanza en un mejor futuro, el papel del gobierno estadounidense en la construcción de esta expectativa era fundamental. Los ciudadanos tenían que aprender a confiar otra vez en las instituciones. Un Nuevo Trato entre los ciudadanos, el gobierno y las instituciones era lo que se necesitaba para recuperar esa confianza.

Las instituciones gubernamentales, a través de distintos programas, comenzaron a diseñar políticas de atención a las necesidades de las poblaciones en situación de emergencia: ayudas económicas para los desempleados, para los huérfanos, viudas y mujeres abandonadas, programas de saneamiento para los barrios marginales de las grandes ciudades, apoyos económicos y de asesoramiento para los pequeños agricultores y propietarios, programas de vivienda, etc., es decir, el diseño de una polííca social.

En Puerto Rico, el Nuevo Trato adquirió matices regionales, los programas de política social en materia de salud, vivienda y alimentación se extendieron a las zonas rurales. En el marco de la Porto Rican Relief Administration (PRRA) se diseñó un plan para que el gobierno estadounidense comprara la South Porto Rico United Co. la central azucarera más grande en Puerto Rico, y la administrara con la participación de los trabajadores, una suerte de cooperativa estatal, ${ }^{15} \mathrm{o}$ de empresa gubernamental.

La propuesta conocida como Plan Chardón fue diseñada, principalmente, por el especialista puertorriqueño en economía agrícola doctor Carlos Chardón. El plan no fue aprobado ni se llevó a cabo, en gran medida, debido a la falta de interés y recursos económicos del propio gobierno estadounidense para comprar

${ }^{15}$ El texto íntegro del Plan Chardón está reproducido en Mathews, op. cit. 
la central. Sin embargo, sí se puso en práctica un programa de formación de cooperativas agrícolas, ${ }^{16}$ con el apoyo económico y técnico del gobierno estadounidense, para producir frutas tropicales y hortalizas.

Los planes y programas en materia agrícola que se pusieron en práctica en Puerto Rico, en el marco del Nuevo Trato, resultaron interesantes porque, por una parte, hubo un interés del gobierno estadounidense por apoyar a los campesinos y a los pequeños productores y, por otra, se favoreció la enseñanza técnica de oficios y destrezas relacionadas con la industria. Aunque no había una definición clara de un modelo económico para Puerto Rico. El acento estaba en crear empleos y modos de subsistencia para la gente en el corto plazo.

Los campesinos y obreros puertorriqueños, así como la gente que acudía a las oficinas de la PRRA para hacer trámites y solicitar ayudas aprendieron a tratar con las instituciones gubernamentales. La asesoría y ayuda económica por parte de los expertos del gobierno estadounidense acercó a los ciudadanos puertorriqueños con las autoridades que los gobernaban. El Nuevo Trato no resolvió los problemas de los campesinos, ni de los obreros puertorriqueños, pero sí los familiarizó con un modelo de gobernar, donde las ayudas y el constante contacto con los funcionarios gubernamentales pasaron a formar parte de su cultura. El éxito de la campaña de Luis Muñoz Marín se debió a que había tenido como preparación, diez años antes, la puesta en práctica de las políticas del Nuevo Trato.

La situación mundial tampoco presentaba un panorama halagador. El gobierno democrático de Madrid era asediado por los militares españoles rebeldes. En 1936 estalló la Guerra Civil. Varios puertorriqueños ${ }^{17}$ tanto en Nueva York como en la isla se unieron a las brigadas internacionales que llegaron a España para luchar por la República.

${ }^{16}$ Los planes específicos se encuentran en el texto del siguiente artículo cuyas fotografías dan cuenta del trabajo en las cooperativas agrícolas, en Tomás de Jesús Castro, "El aspecto obrero de la reconstrucción", en Puerto Rico Ilustrado, año XXVII, núm. 1382, 26 de diciembre, 1936, pp. 16 y 17.

${ }^{17}$ Bernardo Vega menciona la formación de la Brigada Abraham Lincoln, donde participaron puertorriqueños entre otros Jorge y Pablo Carbonell, en Memorias de Bernardo..., p. 227. 
Europa estaba amenazada por los regímenes fascistas de Benito Mussolini en Italia y de Adolf Hitler en Alemania. La República de España cayó en manos del ejército franquista en 1939, hechos que presagiaban ya la Segunda Guerra Mundial, en la que también habrían de participar miles de puertorriqueños como parte del ejército de Estados Unidos.

Los países latinoamericanos, en esta época entidades eminentemente agrarias, luchaban por posicionarse en el sistema mundial y por cohesionar sus propios sistemas políticos. En el Caribe, Cuba atravesaba por un tiempo difícil, ya que continuaba en el poder el presidente Gerardo Machado y Morales, quien gobernó de 1925 a 1933, apoyado por el gobierno estadounidense. Los cubanos residentes en Nueva York, y algunos escritores e intelectuales antimachadistas, ${ }^{18}$ participaban conjuntamente con los puertorriqueños en la realización de mítines de protesta, en la publicación y firma de manifiestos, declaraciones o denuncias.

El movimiento nacionalista que estuvo unido apoyando las huelgas de los trabajadores cañeros de Puerto Rico, en 1934, sufrió un grave enfrentamiento con el gobierno estadounidense. Los nacionalistas celebraban un mitín en Ponce, en marzo de 1937, cuando surgió una provocación por parte de los guardias, los manifestantes fueron balaceados y perseguidos por la policía. El hecho se conoce como la Masacre de Ponce, en ella perdieron la vida 21 nacionalistas y hubo más de 100 heridos.

El gobernador estadounidense de Puerto Rico, Blanton Winship, calificó el hecho como motín. El fiscal designado para analizar las causas de este suceso, Lic. Rafael Pérez Marchand, renunció al caso, alegando diferencias de enfoque con el gobernador. Los nacionalistas y sus asociaciones en Nueva York lograron que una organización estadounidense de abogados, que defendía las libertades civiles, la Civil Liberties Union, hiciera un informe denunciando los atropellos de que fueron víctimas los manifestantes. En este documento se calificaba lo que fue designado como motín por el gobernador, como masacre. El director del informe fue Arthur Garfield Hayes por lo que también se le conoce como Informe Hayes.

${ }^{18}$ El Club Julio Antonio Mella en Harlem fue una de las organizaciones más activas en esta lucha. Uno de los escritores cubanos que participaba con frecuencia en esta organización era Juan Marinello. Recuérdese que el líder estudiantil Julio Antonio Mella fue asesinado en México durante el gobierno de Machado a quien se le responsabilizó por el crimen. 


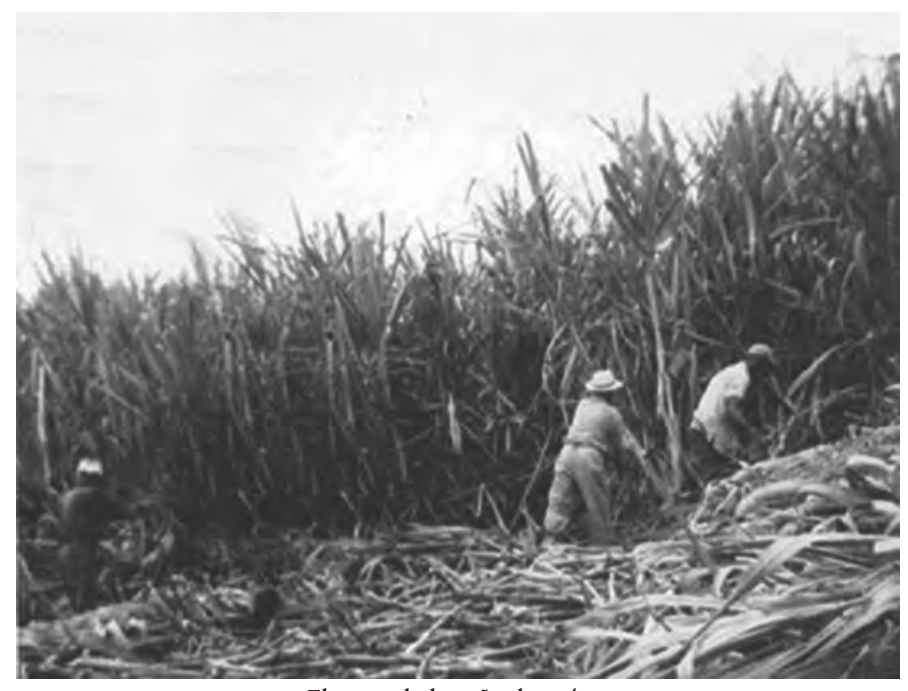

El corte de la caña de azúcar

FuENTE: http://ssdelpepino.com/wp-content/uploads/2009/10/corte-de-cana.jpg

Los CAMPESINOS AL PODER: CAÑa Y REVUeLTA EN PUERTO Rico

El dirigente del nacionalismo puertorriqueño, Pedro Albizu Campos, aceptó dirigir las huelgas de 1934, y reconoció la necesidad de organizar a los trabajadores tanto obreros como campesinos, para ello creó la Asociación de Trabajadores de Puerto Rico, organización que no cumplió sus objetivos, en gran medida, porque su dirigencia no estaba en manos de representantes obreros ni campesinos, y su discurso no pudo convencer a los trabajadores de su militancia.

Los estudiosos de los cambios sociales ${ }^{19}$ han discutido y debatido la posibilidad de que éstos vengan de las masas trabajadoras, generalmente, se ha

19 Carlos Marx en el Manifiesto del Partido Comunista, 4ª ed., México, Editores Mexicanos Unidos, 1981, 107 pp., señalaba que la única clase social que podía hacer una revolución política era el proletariado, al que definía simplemente como los desposeídos: "el proletariado no es ya más que despojo total. No tiene ya ni propiedad, ni individualidad, ni familia, ni leyes, ni moral, ni religión, ni patria: todo está acaparado por la burguesía”. Marx no establece una diferenciación entre obreros y campesinos, ambos son proletarios. Esta categoría analítica prevaleció entre la 
puesto el acento en la organización y mayor formación de los obreros, para atribuirles mejores posibilidades de acceso al poder. Los campesinos, salvo contadas excepciones, no han sido considerados el agente de cambio por excelencia, sino sólo una posibilidad, en gran parte, debido a su falta de organización sindical y formación política.

De forma contraria a estas observaciones, los campesinos puertorriqueños han sido un factor de cambio en su sociedad, aunque sus luchas hayan sido, ciertamente, desorganizadas y rudimentarias en términos de equipamiento y estrategia. Sin embargo, han sido una clase que ha enfrentado de forma abierta y con todos los medios a su alcance, las diferentes políticas patronales y gubernamentales, que han puesto en peligro su manera de vivir.

El discurso del líder nacionalista Pedro Albizu Campos ${ }^{20}$ atrajo la atención de los campesinos cañeros, ya que hacía una fuerte crítica a la presencia estadounidense en la isla. Sin embargo, exigía más sacrificios de parte de la clase trabajadora, no contemplaba otras opciones políticas ni económicas más que la Independencia y, además, justificaba el uso de la violencia en aras del ideal independentista.

Las razones por las que el movimiento nacionalista no pudo captar en sus filas a la gran masa de trabajadores agrícolas puertorriqueños son varias. La discusión apunta hacia la ofensiva que dirigió la propia dirigencia de la FLT ante cualquier disidencia, la falta de planes y programas específicos que incluyeran

mayor parte de los estudiosos de los cambios sociales hasta las primeras décadas del siglo xx. Las revoluciones de carácter campesino del siglo xx: la Revolución mexicana, la Revolución china y la Revolución rusa han obligado a establecer la diferencia y analizar los cambios sociales con otros parámetros.

${ }^{20}$ En el texto del Programa Político, Social y Económico del Partido Nacionalista de Puerto Rico (reproducido en Reece Bothwell González, Puerto Rico 100 años de lucha política, 4 ts. en 5 vols., vol. 1: Programas y Manifiestos (1869-1952), Río Piedras, Editorial Universitaria, 1979, mayo, 1930, p. 463 ) se señalaba: "Condenamos la desconsideración de que son víctimas los colonos de caña de azúcar, a manos de determinadas centrales azucareras, que en fuerza del poderío que ejercen en las zonas donde tienen establecidos sus ingenios, imponen condiciones onerosas en los contratos sobre refacción agrícola y molienda de cañas, viéndose obligados los colonos a aceptar los términos impuestos". Aunque el discurso nacionalista centraba su atención en los pequeños propietarios, es decir, los colonos, los campesinos cañeros veían en estas palabras una denuncia de sus condiciones de trabajo. 
al campesinado puertorriqueño, ${ }^{21}$ el discurso nacionalista que visualizaba a los campesinos como parte de la gran familia puertorriqueña: católica, blanca y de origen hispánico, sin atender a la heterogeneidad que caracterizaba a los campesinos cañeros.

En el tema específico del campo, el nacionalismo perdió la oportunidad de ser el movimiento que abanderara las causas de los trabajadores agrícolas, fundamentalmente por centrar su atención en la causa de la independencia ${ }^{22}$ y no en hacer un exhaustivo análisis de la situación del campo y proponer alternativas al respecto.

La reunión del nacionalismo con las huelgas cañeras representó una oportunidad histórica, única e irrepetible, para los campesinos puertorriqueños de poder tener mayor representatividad como clase social en la escena política de su país y, además, de que sus demandas fueran escuchadas con mayor atención por parte del gobierno estadounidense.

Lastimosamente esta unión fue efímera, representó quizá un momento de angustiosa desesperación para los cañeros que no confiaban ya en sus propios líderes sindicales. El nacionalismo se centró en la causa de la independencia, abandonó a su suerte las demandas de los obreros y los campesinos. Lejos de ayudar a ambas luchas, esta decisión las debilitó a las dos. Los campesinos cañeros siguieron luchando por mejores condiciones de vida durante varias décadas más, sin mayor éxito. El nacionalismo fue brutalmente perseguido y reprimido por el gobierno estadounidense, hasta derivar en otras opciones políticas menos amenazantes para el statu quo en sus discursos y acciones.

${ }^{21}$ A pesar de que don Pedro Albizu Campos reconocía la presencia económica y social de los trabajadores y la importancia de que éstos se organizaran: "Los trabajadores constituyen ya la corporación más fuerte que puede formarse, porque son ellos el verdadero poder y la verdadera fuente de riqueza que tiene la patria", en Pedro Albizu Campos, "La huelga agrícola", en $E l$ Mundo, 16 de enero, 1934, p. 2. Sin embargo, a excepción de la Asociación de Trabajadores de Puerto Rico, que nació para tratar de organizar a los trabajadores, no surgió ninguna otra auténtica organización de los trabajadores puertorriqueños simpatizantes del nacionalismo, ésta fue dirigida por un profesional nacionalista que no era miembro de la clase trabajadora.

${ }^{22}$ Una interesante discusión en cuanto a las causas de la derrota del nacionalismo está en Juan Manuel de la Serna, "Del imperialismo al colonialismo liberal en el Caribe: la experiencia puertorriqueña”, en Cuadernos Americanos, núm. 122, México, octubre-diciembre, 2007, pp. 69-82. 


\section{ConCLUSIÓN}

La década de 1930 representa un parteaguas en la historia contemporánea de América. La clase trabajadora de Estados Unidos y la de los principales países de Europa occidental, cada uno con sus particularidades, se lanzó a una lucha activa por mejorar sus condiciones de vida, en algunos casos los movimientos trascendieron las fronteras de lo laboral para incorporarse a la propuesta de la toma del poder, y el establecimiento de un sistema de gobierno diferente al establecido.

En Puerto Rico, los obreros y campesinos participaron en diversas huelgas y manifestaciones para protestar contra los bajos salarios y la carestía de la vida. La organización sindical puertorriqueña tiene matices particulares porque, en esta época, la mayor central sindical la Federación Libre de los Trabajadores (FLT) aglutinaba, tanto a obreros como a campesinos a través de uniones afiliadas a esta organización. La FLT siguió, en la práctica, un sindicalismo poco congruente con las demandas de los trabajadores, particularmente en el caso de quienes laboraban en la industria de la caña de azúcar.

Grupos de campesinos y obreros de la caña, u obreros agrícolas como se les dice en Puerto Rico, criticaron y rechazaron esta posición de la FLT: "afín al capital". Estos disidentes constituyeron el bastión más importante de resistencia al interior de la FLT, y la única posibilidad de encauzar al sindicalismo puertorriqueño hacia una vía más favorable para las demandas de los trabajadores.

Los dirigentes de los cañeros disidentes se acercaron al líder nacionalista Pedro Albizu Campos, ambos reconocían la importancia de la unión, de formar un movimiento común. Sin embargo, la intransigencia del nacionalismo respecto a las prioridades en la lucha, chocaba con las prioridades de los campesinos cañeros, para los primeros el ideal supremo era la Independencia, para los segundos, lo primero era tener mejores condiciones de vida. El nacionalismo no pudo atraer, mayoritariamente a sus filas al campesinado puertorriqueño porque su discurso y sus planes económicos y políticos no los incluían de una manera heterogénea. Fuera de la denuncia de la explotación de los colonos, el nacionalismo no analizó exhaustivamente el problema económico y social del campo puertorriqueño y no propuso alternativas específicas al respecto. 
Tanto el campesinado puertorriqueño como el nacionalismo tuvieron una única oportunidad de unirse y pelear en un solo movimiento: las huelgas cañeras del 34. Sin embargo, la unión fue efímera. Ambos movimientos, al no luchar juntos por los mismos ideales, no tuvieron la suficiente fuerza, o quizá más bien fueron brutalmente reprimidos y obligados a replegarse, no representando ninguna oposición considerable para que triunfara el populismo liberal de Luis Muñoz Marín, dibujándose un panorama para el pueblo puertorriqueño, más afín a las políticas y planes del gobierno estadounidense para Puerto Rico.

La "derrota" de estos movimientos no significó que no haya existido un intento de los campesinos y obreros puertorriqueños por mejorar sus condiciones de vida. La forma en que ellos asumieron las ideas políticas de liberación, en lo que creían, soñaban o pensaban, no deja de ser un testimonio apasionante de sus luchas cotidianas, más allá de las ideologías, de la militancia y de los partidos políticos.

Recibido: 13 de abril, 2009. Aceptado: 25 de agosto, 2009.

\section{BIBLIOGRAFÍA}

\section{Fuentes primarias}

Censo de Puerto Rico, 1935: Población, edición bilingüe inglés/español, San Juan, Puerto Rico Reconstruction Administration, Oficina del Censo, 1936.

Chart: "Possibilities that exist for additional agriculture industrial enterprises in Porto Rico", ms. núm. 246, Universidad de Puerto Rico, recinto Río Piedras (Col. Puertorriqueña).

Carta confidencial del Lic. Cayetano Coll Cuchí a Santiago Iglesias Pantín, con fecha 23 de octubre, 1934, ubicada en el Centro de Documentación Obrera Santiago Iglesias Pantín, Universidad de Puerto Rico, campus Humacao.

Folleto: "Puerto Rico reclama justicia", en Centro de Documentación Santiago Iglesias Pantín, Universidad de Puerto Rico, campus Humacao. 
Artículos periodísticos de la época

Albizu Campos, Pedro, "La huelga agrícola", en El Mundo, 16 de enero, 1934.

Avilés Bracero, Martín, "Socialismo y Nacionalismo", en El Mundo, 28 de enero, 1934.

De Jesús Castro, Tomás, "El aspecto obrero de la reconstrucción", en Puerto Rico Ilustrado, año XXVII, núm. 1382, 26 de diciembre, 1936, pp. 16-17.

Font Sú́reZ, "Defensa Comunista", en El Mundo, 21 de septiembre, 1933.

Martínez Acosta, C., "Combatiendo el comunismo", en El Mundo, 22 de septiembre, 1933.

\section{Periódicos}

"La producción de azúcar en Puerto Rico", en El Imparcial, 5 de agosto, 1933. "Las condiciones de trabajo en la United Porto Rico Sugar Co.", en El Mundo, 12 de septiembre, 1933.

"Brotes de huelga al comenzar el corte de caña en la Central Coloso", en $E l$ Mundo, 7 de diciembre, 1933.

"La huelga en la Central Coloso", en El Mundo, 11 de diciembre, 1933.

"Se cree que los trabajadores de los muelles de San Juan se declararán en huelga esta semana si no hay arreglo con los patronos", en El Mundo, 18 de diciembre, 1933 .

"Mitin comunista esta noche para respaldar la huelga de los muelles", en $E l$ Mundo, 21 de diciembre, 1933.

"La huelga en la Central Guánica", en El Mundo, 27 de diciembre, 1933.

"Mitin socialista en la Plaza Baldorioty", en Unión Obrera, 16 de enero, 1934.

"Se constituye en Yabucoa la Asociación de Trabajadores", en El Mundo, 18 de enero, 1934.

"La huelga agrícola en la isla", en El Mundo, 23 y 24 de enero, 1934. 
Testimonios

Iglesias Pantín, Santiago, Luchas emancipadoras (crónicas de Puerto Rico), vol. 1, San Juan, Imprenta Venezuela, 1958 [1924].

Justiniano, CARMen Luisa, Con valor y a cómo dé lugar, memorias de una jíbara puertorriqueña, Río Piedras, Editorial de la Universidad de Puerto Rico, 2005 [1994].

MuÑoz MaRín, LuIs, Memorias, autobiografía pública 1898-1940, vol. 1, San Juan, Fundación Luis Muñoz Marín, 2003.

VeGa, BeRnardo, Memorias de Bernardo Vega: contribución a la bistoria de la comunidad puertorriqueña en Nueva York, editadas por César Andreau Iglesias, Río Piedras, Ediciones Huracán, 2002, 278 pp.

Libros

Bothwell González, Reece, Puerto Rico: 100 años de lucha política, t. 1: Programas y manifiestos (1869-1952), Río Piedras, Editorial Universitaria, 1979.

GOODWIn, Barbara, El uso de las ideas políticas, trad. del inglés de Enrique Lynch, Barcelona, Ediciones Península, 1987.

Gould, Lyman J., La Ley Foraker: raíces de la política colonial, trad. del inglés de Jorge Luis Morales, Río Piedras, Editorial Universitaria, 1975 (Col. UPRET).

Gulliem, Mesado, Juan Manuel, Los movimientos sociales en las sociedades campesinas, Madrid, Eudema, 1993.

Hooks, MARGaRET, Tina Modotti, fotógrafa y revolucionaria, trad. del inglés de Susana de los Ángeles Moreno y Margarita González, Barcelona, Plaza y Janés, 1998.

LinARES, ANDRÉs, Historia de los grupos de izquierda en Estados Unidos, Madrid, Castellote Editor, 1976.

Mathews, Thomas, La política puertorriqueña y el Nuevo Trato, trad. del inglés por Antonio J. Colorado, Estado Libre Asociado de Puerto Rico/Editorial del Departamento de Instrucción Pública, 1967.

Rodríguez Vázquez, José Juan, El sueño que no cesa, San Juan, Ediciones Callejón, 2004,523 pp. 
WoOdCOCK, GEORge, El anarquismo. Historia de las ideas y movimientos libertarios, Barcelona, Ariel, 1979.

Artículos de revistas

De la Serna, Juan Manuel, "Del imperialismo al colonialismo liberal en el Caribe: la experiencia puertorriqueña", en Cuadernos Americanos, núm. 122, México, octubre-diciembre, 2007.

OJEDA REYES, FÉLIX, "¿Colonialismo sindical o solidaridad internacional? Las relaciones entre el movimiento obrero puertorriqueño y el norteamericano en los inicios de la Federación Libre (1898-1901)", en Revista de Ciencias Sociales, San Juan, vol. XXVI, núms. 1-4, enero-diciembre, 1987, pp. 311-342.

Pérez Velasco, EricK, "La condición obrera en Puerto Rico (1898-1920)", en Plural (Revista de la Administración de Colegios Regionales de Puerto Rico), vol. 3, núms. 1-2, enero-diciembre, 1984. 